\title{
Going beyond GDP with a parsimonious indicator: Inequality-adjusted healthy lifetime income
}

\author{
David E. Bloom ${ }^{1}$, Victoria Y. Fan ${ }^{2}$, Vadim Kufenko ${ }^{3}$, Osondu Ogbuojï, \\ Klaus Prettner ${ }^{5,6}$ and Gavin Yamey ${ }^{4}$
}

\section{Abstract}

Per capita GDP has limited use as a well-being indicator because it does not capture many dimensions that imply a "good life", such as health and equality of opportunity. However, per capita GDP has the virtues of being easy to interpret and to calculate with manageable data requirements. Against this backdrop, there is a need for a measure of well-being that preserves the advantages of per capita GDP, but also includes health and equality. We propose a new parsimonious indicator to fill this gap, and calculate it for 149 countries. This new indicator could be particularly useful in complementing standard well-being indicators during the COVID-19 pandemic. This is because (i) COVID-19 predominantly affects older adults beyond their prime working ages whose mortality and morbidity do not strongly affect GDP, and (ii) COVID-19 is known to have large effects on inequality in many countries.

Keywords: beyond GDP; well-being; health; inequality; human development; lifetime income; COVID-19

\footnotetext{
${ }^{1}$ Harvard T.H. Chan School of Public Health, Boston, MA, USA

${ }^{2}$ University of Hawai'i at Mānoa, Office of Public Health Studies, Myron B. Thompson School of Social Work, Honolulu, HI, USA

${ }^{3}$ University of Hohenheim, Stuttgart, Germany

${ }^{4}$ Duke University, Duke Global Health Institute, Durham, NC, USA

${ }^{5}$ Vienna University of Economics and Business, Vienna, Austria

${ }^{6}$ Vienna Institute of Demography (OeAW), Wittgenstein Centre for Demography and Global Human Capital (IIASA, OeAW, University of Vienna), Vienna, Austria

${ }^{*}$ Correspondence to: Klaus Prettner, Klaus.Prettner@wu.ac.at
} 


\section{Introduction}

Per capita GDP has limited use in measuring well-being. The reasons why this is the case are well known: ${ }^{1}$ for example, per capita GDP does not capture negative externalities of production, catastrophes increase GDP because of reconstruction efforts and GDP does not take into account the quality of the natural environment. Most importantly - and partly as a consequence of these shortcomings - per capita GDP disregards generally desired aspects such as living a long and healthy life, or providing larger parts of the population the opportunity to share in the gains of economic prosperity (Fitoussi et al. 2009; Jones and Klenow 2016; Fan et al. 2018; Lutz et al. 2018; Bloom et al. forthcoming).

The following comparison between Germany and Iceland in 2013 illustrates the consequences of these omissions. According to the World Bank (2019), the two countries had comparable levels of GDP per capita (USD42,914 and USD42,372, respectively, adjusted for purchasing power). Thus, based on these numbers, one would surmise that the typical German was slightly better off than the typical Icelander. However, this misses the point that life expectancy at birth was 80.49 years in Germany, compared with 82.06 years in Iceland. Even if we disregard the intrinsic value of health, this implies that the lifetime income of the average Icelander under current conditions (calculated as life expectancy multiplied by GDP per capita) was higher than that of the average German. Similarly, the Gini index of income inequality in Germany stood at 31.1 (expressed in per cent) and at 25.4 in Iceland. Considering that income distributions are skewed towards higher incomes, this implies that the median Icelander was likely to be better off financially than the median German, even when disregarding differences in lifetime horizons.

Despite the problems outlined above, per capita GDP does have the virtues of being easy to interpret and to calculate with manageable data requirements. Against this backdrop, there is a need for a measure that combines the advantages of per capita GDP with the virtues of including health and equality. In the following, we propose inequality-adjusted healthy lifetime income (IHLI) as such an indicator. The resulting number, expressed in PPP-adjusted dollars, refers to the amount that a new-born in a certain economy can expect to earn over the years in which she is in good health under the given economic and health conditions, and adjusted for the level of inequality.

Our new indicator, IHLI, could be a useful complement to standard well-being indicators, particularly during periods in which levels of health and inequality change drastically. The current COVID-19 pandemic represents just such a situation, because (i) COVID-19 predominantly affects older adults beyond their prime working ages whose mortality and morbidity do not strongly affect GDP, and (ii) COVID-19 is known to have large effects on inequality in many countries.

\footnotetext{
1 Simon Kuznets, who is credited with the original formulation of GDP, already warned against its use as a welfare measure.
} 
Even though IHLI is able to address some of the shortcomings of standard wellbeing measures, it also has limitations: for example, (i) it does not include measures related to education; (ii) it is more difficult to compute and requires more data than per capita GDP; and (iii) it depends on the quality of the underlying health measure, which is known to be difficult to estimate across different countries. Thus, of course, we do not propose IHLI as a substitute for other indicators. We simply hope that IHLI provides additional valuable information for policymakers and the general public.

\section{Inequality-adjusted healthy lifetime income}

Several indicators have been proposed to address the problems of per capita GDP as a well-being measure, including the Human Development Index (HDI), the Happy Planet Index, the Resource-Infrastructure-Environment (RIE) index, Gross National Happiness and the Better Life Index (see ul Haq 2003; Natoli and Zuhair 2011; Fan et al. 2018; OECD 2019; New Economics Foundation 2019; for detailed information). For example, the HDI considers three components, gross national income (GNI), life expectancy and schooling, and merges the sub-indices constructed out of these components into a single overall index. This index is then used to create country league tables with a country's rank being a proxy for its development level. A similar approach has been proposed by Natoli and Zuhair (2011) in their RIE, with the sub-components comprising indices for the availability of resources, the availability of infrastructure and the quality of the environment.

While these alternative indicators represent highly valuable improvements over GDP along several dimensions, they also tend to have high data requirements (on issues such as schooling, environmental quality, housing, civic engagement and work-life balance). Moreover, these indicators are often based on subjective evaluations of life satisfaction or happiness that are collected by polling a small subset of the population, and they are often hard to interpret because different components with incompatible units of measurement are meshed together to construct an overall index. As an illustration, consider the HDI (ul Haq 2003; Klugman et al. 2011). Because this indicator's components of income, life expectancy and education are measured in different units, an overall index ranging from zero to one must be constructed out of the different components' sub-indices. The resulting index lacks an economic interpretation, and has an upper limit of one by construction. The upper limit implies that further development cannot change the index value appreciably, and that well-developed countries tend to cluster at index values close to one. Thus, at the upper end of the distribution, only marginal differences across countries may be evident in the index value, while the underlying fundamental data on life expectancy, income and schooling could differ substantially.

To address the trade-off of including additional dimensions of economic wellbeing, while ensuring that the indicator remains easy to calculate, easy to interpret and based on readily available data, we propose using inequality-adjusted healthy 
lifetime income (IHLI) as a novel and complementary measure of economic wellbeing. This measure consists of the following components: (i) GDP per capita adjusted for purchasing power (pppGDPpc) to capture a country's material living standard; (ii) healthy life expectancy at birth (HALE) to capture health-related aspects such as environmental quality and access to high-quality medical facilities; and (iii) an inverse measure of the Gini coefficient (1-Gini) as a proxy for an average person's opportunities to benefit from economic progress (Sen 1976). ${ }^{2}$ The following straightforward formulation of the indicator

$$
I H L I_{i}=p p p G D P p c_{i} \times H A L E_{i} \times\left(1-G i n i_{i}\right)
$$

implies that it should be interpreted as reflecting the amount that a new-born in economy $i$ can expect to earn over the years in which she is in good health under the given economic and health conditions, and adjusted for the level of inequality. Note that the unitary weights of the different components in this formulation follow mathematically from the underlying units of the different components: since the outcome is inequality-adjusted healthy lifetime income, it does not make sense to use a different weighting scheme in Equation (1). ${ }^{3}$

Using the World Bank's (2019) World Development Indicators on pppGDPpc in international dollars with a base year of 2011, the WHO's (2014) Global Health Observatory database on HALE in years and Solt's (2019) Standardized World Income Inequality Database on the Gini coefficient of disposable income, we calculate this indicator for the year 2010 for all countries for which the necessary data inputs are available. Table A.1 in the appendix displays the results. The first column shows each country's rank as measured by the IHLI indicator; the second column provides each country's name; the third to fifth columns show the three components of IHLI; and the sixth column reports the IHLI value.

Interestingly, the IHLI indicator alters some standard rankings that are based solely on per capita GDP. For example, among high-income countries, the United States and Saudi Arabia have comparatively low IHLI values despite their high per capita GDP because of their rather low values for healthy life expectancy and rather high inequality levels. By contrast, some European countries, such as Austria, Belgium, Denmark and Sweden, have comparatively high IHLI values despite their lower per capita GDP because they have rather high healthy life expectancy values and rather low inequality levels.

\footnotetext{
2 While there are discussions on the issue of whether a single measure of inequality can capture the entire distribution reasonably well, the Gini coefficient possesses some desirable properties in this regard, and it also tends to be strongly correlated with other inequality measures. For discussions, see Cowell (2011) and Ferreira (2020).

3 To see why this is the case, consider the following analogue. Assume that we would like to calculate the distance travelled by a car within a certain time span. Then we need to multiply the speed of the car by the duration of the travel. Applying a different weight to the speed of the car and the duration of the travel would be meaningless.
} 
The differences between the traditional ranking based on per capita GDP values and the ranking based on the IHLI indicator can be decomposed into the contributions of the two additional components: the correlation between the differences in the country league table based on per capita GDP and the country league table based on IHLI is -0.654 for the Gini index and 0.299 for HALE, with both coefficients being significant at the $1 \%$ level. Thus, changes in the Gini coefficient contribute relatively more in changing the ranking, which is due to the fact that there is more cross-country variation in this variable than in HALE. While it is not uncommon for Gini indices between countries to differ by a factor of two, this is generally not the case for HALE. Overall, considering the additional dimensions of healthy life expectancy and inequality may contribute substantially to revising the ranking of the countries to account for well-being.

While the adjustments discussed above seem reasonable, we compare IHLI with some obvious alternatives - the HDI and its inequality-adjusted version (Hicks 1997; UNDP 2017) - to assess whether the different well-being indicators yield country rankings that are generally in line with one another. This is important, because if the ranking based on IHLI differs substantially from the ranking based on an established indicator such as the HDI and its inequality-adjusted version, it is likely that IHLI is not well suited for assessing cross-country differences in wellbeing. In our comparison, we need to restrict the dataset to 120 countries because the inequality-adjusted HDI is only available for this subset.

Figure 1 displays the correlation between the country rankings based on the IHLI and the HDI (left diagram; correlation coefficient: 0.9710) and between the IHLI and the inequality-adjusted HDI (right diagram; correlation coefficient: 0.9536). Overall, this analysis shows a strong positive correlation between the rankings based on the different indicators. This result is reassuring, as a different outcome might indicate that we are not measuring well-being accurately, and might therefore be missing important well-being dimensions that the HDI captures. Even though the different measures lead to consistent country rankings, our proposed indicator has the following advantages:

- It has a direct and immediate economic interpretation.

- It does not depend on aggregating different sub-indicators that are based on incompatible units of measurement.

- It is not restricted to a value between zero and one, and is thus not bounded from above, which allows for further development to be measured accurately, and avoids a clustering of countries at the upper bound of the index.

- It is parsimonious in terms of its computation and data input requirements.

- It can be obtained for more countries.

- The weights of its components follow directly from the interpretation of the indicator. 
Figure 1:

Comparison between IHLI and HDI rankings, 2010 (left diagram: HDI; right diagram: inequality-adjusted HDI)
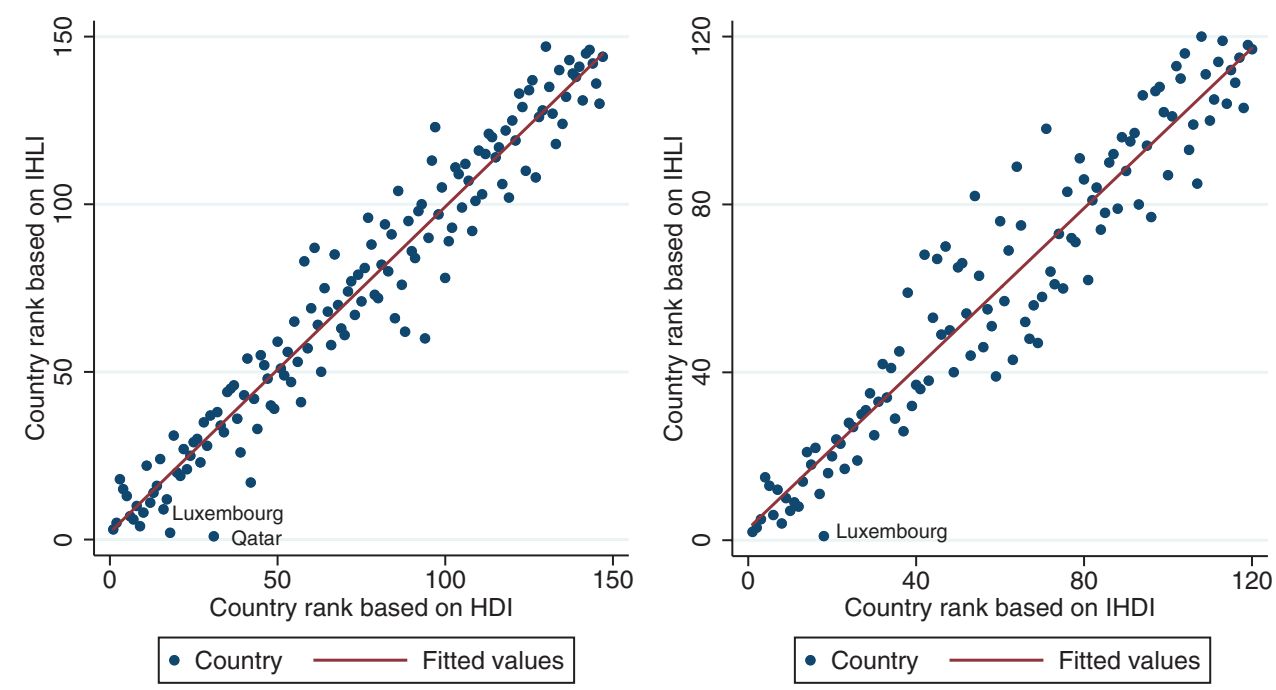

\section{Variants of IHLI}

We view the formulation of IHLI in Equation (1) as an important improvement over per capita GDP. However, using gross national income (GNI) per capita instead of GDP per capita to measure income may prove useful because particularly small, open economies such as Luxembourg are highly dependent on commuters. In this case, GNI might capture income better than GDP because GNI counts only residents' income. In this case, our indicator would change to

$$
I H L I_{i, g n i}=p p p G N I p c_{i} \times H A L E_{i} \times\left(1-G i n i_{i}\right)
$$

where $p p p G N I p c$ is the ppp-adjusted GNI, and the subscript in the indicator name signifies the use of GNI instead of GDP in the calculation.

Moreover, HALE itself is subject to criticism because it is defined as weighted life expectancy over a complete set of health states, with the weights being between zero (dead) and one (optimal health), as described in Sullivan (1971), Murray et al. (2002) and WHO (2014). ${ }^{4}$ Thus, detailed morbidity data (on years of healthy life lost due to disability, YLD) are required to construct HALE, and these data might

\footnotetext{
4 We are grateful to two referees who suggested delving more deeply into the problems with using HALE as an indicator of healthy life expectancy.
} 
not be available for all countries over long time spans. In addition, the morbidity data are very difficult to estimate and the methods for their calculation change over time. Thus, while it would be ideal to construct our indicator with a measure of healthy life expectancy, another variant of the proposed indicator could rely on life expectancy at birth (LEXP) instead of HALE. Life expectancy arguably captures health less well than HALE, but it might be available for more countries and more time periods, which could allow for an extension of the sample when reconstructing the index over the past decades. Furthermore, life expectancy is easier to calculate, and is not subject to changes in the method of its calculation over time. In this case, the indicator would need to be renamed inequality-adjusted lifetime income (ILI), and the formula would change to

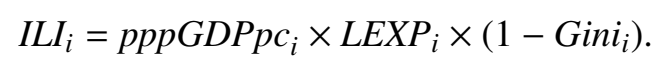

As yet another version, we could use life expectancy conditional on reaching a certain age, such as age 20, instead of life expectancy at birth in the construction of the indicator. In this case, we would have the formula

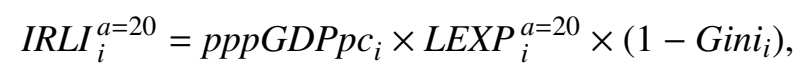

where the interpretation of the indicator changes to inequality-adjusted remaining lifetime income (IRLI), and the superscript indicates conditioning on age 20. In addition, we would need to keep in mind that this version of the indicator disregards potentially important information on child mortality.

\section{Limitations}

Of course, no welfare measure is perfect, and the IHLI also has many limitations. For example, (i) per capita GDP might not be the best proxy of lifetime income because it does not reflect the future growth potential of an economy. If a country has a strong potential for economic growth over the coming decades, then a child born into this economy could expect to earn a much higher lifetime income than a child born into a stagnant or even shrinking economy. However, adjusting for the growth potential of an economy is very complicated, because economic growth can sometimes stall rather unexpectedly (witness Japan in the 1990s, or the global economy during the COVID-19 crisis). (ii) Period healthy life expectancy might not be a good proxy of cohort healthy life expectancy. If mortality continues to decrease for all age groups, a child born today can reasonably expect to outlive current period life expectancy. For this reason, our indicator is on the conservative side. (iii) Income inequality is assumed to be stable over the life cycle, which is generally not the case. (iv) Income inequality is assumed to be a good proxy for health inequality, which might not always be true. (v) Like standard aggregate macroeconomic indicators, this indicator disregards race, gender, migration status, etc. Finally, (vi) in contrast to the HDI and the IHDI, the IHLI lacks the education 
dimension, which would be difficult to add in terms of interpretation. Overall, of course, we do not claim that our indicator eliminates all of the problems of established indicators, and that it should replace them. Rather, we merely suggest that IHLI solves some of the problems of standard well-being measures, and that it might be worthwhile to report IHLI alongside other indicators.

\section{Conclusions}

We have proposed a novel indicator for measuring economic well-being that accounts for income, health and inequality, and that can be readily interpreted as inequality-adjusted healthy lifetime income. Although this indicator captures more dimensions of well-being than per capita GDP, it nevertheless remains easy to calculate and easy to interpret, and it requires limited data. A country ranking for the year 2010 shows some reasonable deviations from a ranking based on per capita GDP. While the IHLI-based country rankings are consistent with the rankings based on other established indicators such as the HDI, the IHLI does not share the HDI's shortcomings, and it is available for more countries (149 countries instead of 120 countries for the inequality-adjusted HDI). It might be useful to develop different versions of the indicator in order to further increase the availability of data, and to adjust for distortions that are caused by commuting into small, open economies. Overall, our proposed indicator might allow for better comparisons of well-being across countries and over time.

However, we do not advocate abandoning per capita GDP, as it continues to be a highly valuable gauge of the economic strength of a country. Per capita GDP has many advantages over other proposed indicators because it includes both capital income and wage income. If only the wage level is considered, capital income, which is a substantial source of income for many people, is neglected. If only consumption measures are considered, saving/investment and borrowing are disregarded. In addition, per capita GDP is available over long periods and for many countries, which is typically not the case for alternative income measures.

\section{Acknowledgements}

Vadim Kufenko gratefully acknowledges the support provided by the Faculty of Business, Economics, and Social Sciences at the University of Hohenheim within its research focus "Inequality and Economic Policy Analysis (INEPA)". We would like to thank the managing editor of the Vienna Yearbook of Population Research, Maria Winkler-Dworak; two anonymous referees; Vanessa di Lego; Tora Estep; Bernhard Hammer; Michael Kuhn; Wolfgang Lutz; Erich Strießnig; Joshua Wilde; the participants of the Wittgenstein Centre conference "Demographic Aspects of Human Well-Being"; and the participants of the 19th meeting of German, Austrian and Swiss demographers (DACH19) for their valuable comments and suggestions. 


\section{References}

Bloom, D. E., M. Kuhn and K. Prettner 2020. Modern infectious diseases: Macroeconomic impacts and policy responses. Journal of Economic Literature (forthcoming).

Cowell, F. 2011. Measuring inequality. London School of Economics Perspectives in Economic Analysis. Oxford, UK: Oxford University Press.

Fan V. Y., D. E. Bloom, O. Ogbuoji, K. Prettner and G. Yamey 2018. Valuing health as development: Going beyond gross domestic product. The BMJ 363: k4371. https://doi.org/10.1136/bmj.k4371

Ferreira, F. 2020. In defense of the Gini coefficient. URL: https://blogs.worldbank.org/ developmenttalk/defense-gini-coefficient, accessed on 31 July 2020.

Fitoussi, J. P., A. Sen and J. Stiglitz 2009. Report by the commission on the measurement of economic performance and social progress. The Commission on the Measurement of Economic Performance and Social Progress. Paris, France.

Hicks, D. A. 1997. The inequality-adjusted human development index: A constructive proposal. World Development 25(8): 1283-1298. https://doi.org/10.1016/S0305-750X(97) 00034-X

Jones, C. I. and P. J. Klenow 2016. Beyond GDP? Welfare across countries and time. American Economic Review 106(9): 2426-2457. https://doi.org/10.1257/aer.20110236

Klugman, J., F. Rodriguez and H. J. Choi 2011. The HDI 2010: New controversies, old critiques. The Journal of Economic Inequality 9(2): 249-288. https://doi.org/10.1007/ s10888-011-9178-z

Lutz, W., A. A. Lijadi, E. Striessnig, A. Dimitrova and M. Caldeira Brant de Souza Lima 2018. Years of good life (YoGL): A new indicator for assessing sustainable progress. IIASA Working Paper WP-18-007, Laxenburg, Austria.

Murray, C. J. I., J. A. Salomon, C. D. Mathers and A. D. Lopez 2002. Summary measures of population health. Concepts, ethics, measurement, and applications. Geneva, Switzerland: World Health Organization.

Natoli, R. and S. Zuhair 2011. Measuring progress: A comparison of the GDP, HDI, GS and the RIE. Social Indicators Research 103(1): 33-56. https://doi.org/10.1007/s11205-0109695-3

New Economics Foundation 2019. Happy planet index. http://happyplanetindex.org/countries, accessed on 18 August 2019.

OECD (Organisation for Economic Co-operation and Development) 2019. Better life index. http://www.oecdbetterlifeindex.org/\#/11111111111, accessed on 8 August 2019.

Sen, A. 1976. Real national income. The Review of Economic Studies 43(1): 19-39.

Solt, F. 2019. Measuring income inequality across countries and over time: The standardized world income inequality database. SWIID Version 8.1, May 2019. https://fsolt.org/swiid/, accessed on 20 May 2019.

Sullivan, D. F. 1971. A single index of mortality and morbidity. HSMHA Health Reports 86: 347-354.

ul Haq, M. 2003. The birth of the human development index. In: Readings in human development, Oxford. https://sites.hks.harvard.edu/cid/events/papers/ulhaqhumandevelopindexchap_030201.pdf 
UNDP (United Nations Development Programme) 2017. Human development reports: data. http://hdr.undp.org/en/data, accessed on 20 May 2019.

World Bank 2019. World development indicators. http://datatopics.worldbank.org/worlddevelopment-indicators/, accessed on 20 May 2019.

WHO (World Health Organization) 2014. WHO methods for life expectancy and healthy life expectancy. https://www.who.int/healthinfo/statistics/LT_method_1990_2012.pdf, accessed on 31 July 2020.

WHO (World Health Organization) 2019. Global health observatory (GHO) data. https://www.who.int/gho/mortality_burden_disease/life_tables/hale/en/, accessed on 20 May 2019.

\section{Appendix}

Table A.1:

Ranking of countries according to the IHLI indicator as of 2010

\begin{tabular}{llcccc}
\hline Rank & Country & pppGDPpc & HALE & Gini & IHLI \\
\hline 1 & Qatar & 125,141 & 66.7 & 0.397 & $5,033,177$ \\
2 & Luxembourg & 91,743 & 71.7 & 0.280 & $4,736,156$ \\
3 & Norway & 62,350 & 71.8 & 0.246 & $3,375,477$ \\
4 & Singapore & 72,116 & 74.8 & 0.393 & $3,274,319$ \\
5 & Switzerland & 55,866 & 72.5 & 0.290 & $2,875,718$ \\
6 & Netherlands & 46,102 & 71.4 & 0.265 & $2,419,374$ \\
7 & Denmark & 43,998 & 70.4 & 0.253 & $2,313,825$ \\
8 & Sweden & 42,989 & 71.9 & 0.254 & $2,305,808$ \\
9 & Austria & 43,336 & 71.4 & 0.282 & $2,221,639$ \\
10 & Ireland & 43,515 & 71.5 & 0.298 & $2,184,136$ \\
11 & Belgium & 41,086 & 70.8 & 0.257 & $2,161,300$ \\
12 & Iceland & 40,137 & 72.6 & 0.260 & $2,156,306$ \\
13 & United States & 49,479 & 68.7 & 0.370 & $2,141,511$ \\
14 & Finland & 39,848 & 70.4 & 0.254 & $2,092,760$ \\
15 & Germany & 40,429 & 70.9 & 0.287 & $2,043,741$ \\
16 & Canada & 40,699 & 72.2 & 0.311 & $2,024,622$ \\
17 & Oman & 45,336 & 65.5 & 0.319 & $2,022,228$ \\
18 & Australia & 41,464 & 72.2 & 0.329 & $2,008,775$ \\
19 & France & 36,815 & 72.2 & 0.294 & $1,876,574$ \\
20 & Japan & 35,750 & 73.8 & 0.314 & $1,809,896$ \\
21 & Italy & 36,201 & 72.8 & 0.331 & $1,763,112$ \\
22 & United Kingdom & 36,509 & 71.3 & 0.335 & $1,731,046$ \\
23 & Cyprus & 33,913 & 72.4 & 0.298 & $1,723,636$ \\
\hline
\end{tabular}

Continued 
Table A.1:

\section{Continued}

\begin{tabular}{|c|c|c|c|c|c|}
\hline Rank & Country & pppGDPpc & HALE & Gini & IHLI \\
\hline 24 & New Zealand & 32,119 & 72.0 & 0.319 & $1,574,869$ \\
\hline 25 & Spain & 32,507 & 72.9 & 0.337 & $1,571,156$ \\
\hline 26 & Saudi Arabia & 45,421 & 64.4 & 0.478 & $1,526,916$ \\
\hline 27 & Slovenia & 28,678 & 69.2 & 0.247 & $1,494,361$ \\
\hline 28 & Malta & 28,359 & 71.6 & 0.272 & $1,478,194$ \\
\hline 29 & Czech Republic & 28,353 & 68.1 & 0.253 & $1,442,334$ \\
\hline 30 & Greece & 28,726 & 71.5 & 0.332 & $1,372,015$ \\
\hline 31 & Israel & 29,665 & 72.4 & 0.369 & $1,355,242$ \\
\hline 32 & Portugal & 27,238 & 70.8 & 0.337 & $1,278,584$ \\
\hline 33 & Slovak Republic & 25,159 & 66.8 & 0.257 & $1,248,705$ \\
\hline 34 & Bahamas, The & 29,222 & 66.4 & 0.439 & $1,088,531$ \\
\hline 35 & Hungary & 22,405 & 65.6 & 0.271 & $1,071,469$ \\
\hline 36 & Estonia & 22,741 & 66.7 & 0.323 & $1,026,889$ \\
\hline 37 & Croatia & 20,758 & 67.9 & 0.277 & $1,019,027$ \\
\hline 38 & Poland & 21,771 & 67.3 & 0.313 & $1,006,568$ \\
\hline 39 & Lithuania & 21,071 & 64.5 & 0.335 & 903,772 \\
\hline 40 & Kazakhstan & 20,097 & 60.2 & 0.261 & 894,052 \\
\hline 41 & Malaysia & 21,107 & 65.6 & 0.412 & 814,166 \\
\hline 42 & Seychelles & 20,365 & 64.6 & 0.410 & 776,196 \\
\hline 43 & Belarus & 16,261 & 62.3 & 0.245 & 764,841 \\
\hline 44 & Romania & 17,469 & 65.2 & 0.331 & 761,983 \\
\hline 45 & Latvia & 18,252 & 64.6 & 0.357 & 758,145 \\
\hline 46 & Argentina & 18,712 & 67.3 & 0.399 & 756,852 \\
\hline 47 & Chile & 19,442 & 68.9 & 0.453 & 732,738 \\
\hline 48 & Iran, Islamic Rep. & 17,943 & 63.9 & 0.382 & 708,566 \\
\hline 49 & Uruguay & 17,082 & 68.0 & 0.393 & 705,093 \\
\hline 50 & Lebanon & 16,452 & 65.2 & 0.348 & 699,371 \\
\hline 51 & Turkey & 17,959 & 64.4 & 0.404 & 689,319 \\
\hline 52 & Venezuela, RB & 16,545 & 65.7 & 0.380 & 673,943 \\
\hline 53 & Bulgaria & 15,283 & 65.7 & 0.332 & 670,746 \\
\hline 54 & Mauritius & 15,938 & 64.5 & 0.366 & 651,770 \\
\hline 55 & Montenegro & 14,038 & 67.1 & 0.312 & 648,082 \\
\hline 56 & Barbados & 16,425 & 66.2 & 0.469 & 577,372 \\
\hline 57 & Panama & 15,629 & 68.3 & 0.473 & 562,537 \\
\hline 58 & Mexico & 15,716 & 66.5 & 0.463 & 561,225 \\
\hline 59 & Algeria & 12,871 & 64.5 & 0.324 & 561,184 \\
\hline 60 & Serbia & 12,688 & 66.2 & 0.339 & 555,208 \\
\hline 61 & Iraq & 12,718 & 59.6 & 0.302 & 529,062 \\
\hline
\end{tabular}

Continued 
Table A.1:

Continued

\begin{tabular}{|c|c|c|c|c|c|}
\hline Rank & Country & pppGDPpc & HALE & Gini & IHLI \\
\hline 62 & Thailand & 13,487 & 65.5 & 0.406 & 524,722 \\
\hline 63 & Gabon & 15,356 & 54.8 & 0.393 & 510,789 \\
\hline 64 & Brazil & 14,539 & 64.5 & 0.463 & 503,583 \\
\hline 65 & North Macedonia & 11,355 & 66.5 & 0.347 & 493,099 \\
\hline 66 & Costa Rica & 13,000 & 69.7 & 0.456 & 492,918 \\
\hline 67 & Maldives & 12,006 & 67.6 & 0.400 & 486,943 \\
\hline 68 & Tunisia & 10,436 & 65.1 & 0.377 & 423,271 \\
\hline 69 & St. Lucia & 11,788 & 65.7 & 0.459 & 419,006 \\
\hline 70 & Albania & 9,927 & 66.4 & 0.383 & 406,705 \\
\hline 71 & Jordan & 9,473 & 64.7 & 0.346 & 400,829 \\
\hline 72 & Bosnia and Herzegovina & 9,720 & 66.7 & 0.394 & 392,885 \\
\hline 73 & Dominican Republic & 11,133 & 63.8 & 0.455 & 387,090 \\
\hline 74 & China & 9,526 & 67.6 & 0.430 & 367,049 \\
\hline 75 & Colombia & 10,791 & 65.7 & 0.498 & 355,903 \\
\hline 76 & Ukraine & 7,824 & 62.2 & 0.270 & 355,279 \\
\hline 77 & Egypt, Arab Rep. & 9,859 & 60.0 & 0.404 & 352,555 \\
\hline 78 & Peru & 9,957 & 66.3 & 0.469 & 350,524 \\
\hline 79 & Timor-Leste & 8,861 & 57.3 & 0.314 & 348,289 \\
\hline 80 & Ecuador & 9,352 & 66.8 & 0.443 & 347,978 \\
\hline 81 & Paraguay & 9,801 & 64.5 & 0.463 & 339,455 \\
\hline 82 & Jamaica & 7,999 & 66.1 & 0.409 & 312,489 \\
\hline 83 & Mongolia & 7,709 & 60.2 & 0.333 & 309,526 \\
\hline 84 & Sri Lanka & 8,530 & 66.1 & 0.488 & 288,668 \\
\hline 85 & Botswana & 13,053 & 52.9 & 0.589 & 283,793 \\
\hline 86 & Armenia & 6,703 & 65.2 & 0.360 & 279,696 \\
\hline 87 & Indonesia & 8,433 & 60.4 & 0.456 & 277,104 \\
\hline 88 & Georgia & 6,982 & 64.8 & 0.401 & 270,989 \\
\hline 89 & Fiji & 7,352 & 60.4 & 0.393 & 269,548 \\
\hline 90 & Morocco & 6,443 & 63.5 & 0.398 & 246,306 \\
\hline 91 & South Africa & 11,888 & 50.5 & 0.594 & 243,736 \\
\hline 92 & El Salvador & 6,301 & 64.2 & 0.407 & 239,874 \\
\hline 93 & Bhutan & 6,420 & 58.7 & 0.395 & 227,985 \\
\hline 94 & Guatemala & 6,714 & 62.1 & 0.467 & 222,230 \\
\hline 95 & Samoa & 5,400 & 64.4 & 0.414 & 203,783 \\
\hline 96 & Philippines & 5,597 & 60.6 & 0.416 & 198,074 \\
\hline 97 & Tonga & 4,984 & 63.7 & 0.377 & 197,798 \\
\hline 98 & Cabo Verde & 5,828 & 63.1 & 0.481 & 190,869 \\
\hline 99 & Vietnam & 4,408 & 66.5 & 0.376 & 182,921 \\
\hline 100 & Namibia & 8,461 & 53.4 & 0.600 & 180,724 \\
\hline
\end{tabular}

Continued 
Table A.1:

Continued

\begin{tabular}{|c|c|c|c|c|c|}
\hline Rank & Country & pppGDPpc & HALE & Gini & IHLI \\
\hline 101 & Bolivia & 5,407 & 61.0 & 0.453 & 180,431 \\
\hline 102 & Congo, Rep. & 5,186 & 54.2 & 0.422 & 162,476 \\
\hline 103 & Pakistan & 4,284 & 56.2 & 0.342 & 158,406 \\
\hline 104 & Yemen, Rep. & 4,479 & 54.3 & 0.359 & 155,888 \\
\hline 105 & Lao PDR & 4,219 & 56.0 & 0.351 & 153,327 \\
\hline 106 & Moldova & 3,911 & 61.3 & 0.362 & 152,951 \\
\hline 107 & Nicaragua & 4,029 & 65.5 & 0.429 & 150,676 \\
\hline 108 & Myanmar & 3,721 & 56.3 & 0.328 & 140,787 \\
\hline 109 & India & 4,463 & 57.4 & 0.469 & 136,035 \\
\hline 110 & Nigeria & 5,083 & 46.2 & 0.421 & 135,969 \\
\hline 111 & Honduras & 3,971 & 65.5 & 0.498 & 130,576 \\
\hline 112 & Mauritania & 3,317 & 54.5 & 0.358 & 116,058 \\
\hline 113 & Micronesia, Fed. Sts. & 3,298 & 60.3 & 0.417 & 115,929 \\
\hline 114 & Vanuatu & 2,948 & 62.0 & 0.374 & 114,419 \\
\hline 115 & Kyrgyz Republic & 2,790 & 61.1 & 0.341 & 112,346 \\
\hline 116 & Sao Tome and Principe & 2,642 & 59.0 & 0.302 & 108,783 \\
\hline 117 & Bangladesh & 2,443 & 60.7 & 0.339 & 98,009 \\
\hline 118 & Ghana & 3,059 & 54.1 & 0.412 & 97,321 \\
\hline 119 & Cambodia & 2,523 & 58.5 & 0.343 & 96,967 \\
\hline 120 & Senegal & 2,725 & 56.1 & 0.392 & 92,931 \\
\hline 121 & Cameroon & 2,930 & 48.3 & 0.431 & 80,520 \\
\hline 122 & Kenya & 2,476 & 55.5 & 0.442 & 76,677 \\
\hline 123 & Zambia & 3,279 & 50.1 & 0.540 & 75,574 \\
\hline 124 & Nepal & 1,986 & 59.2 & 0.362 & 75,010 \\
\hline 125 & Tajikistan & 2,106 & 62.4 & 0.440 & 73,603 \\
\hline 126 & Côte d'Ivoire & 2,690 & 46.2 & 0.410 & 73,331 \\
\hline 127 & Solomon Islands & 1,871 & 60.6 & 0.419 & 65,888 \\
\hline 128 & Comoros & 2,426 & 54.7 & 0.529 & 62,507 \\
\hline 129 & Afghanistan & 1,694 & 51.6 & 0.302 & 61,004 \\
\hline 130 & Benin & 1,819 & 51.7 & 0.447 & 51,999 \\
\hline 131 & Lesotho & 2,366 & 45.7 & 0.523 & 51,568 \\
\hline 132 & Chad & 1,925 & 45.1 & 0.414 & 50,880 \\
\hline 133 & Guinea & 1,574 & 50.0 & 0.369 & 49,645 \\
\hline 134 & Gambia, The & 1,644 & 52.5 & 0.426 & 49,549 \\
\hline 135 & Madagascar & 1,386 & 55.8 & 0.417 & 45,078 \\
\hline 136 & Uganda & 1,516 & 50.4 & 0.413 & 44,847 \\
\hline 137 & Zimbabwe & 1,738 & 46.7 & 0.453 & 44,396 \\
\hline
\end{tabular}

Continued 
Table A.1:

Continued

\begin{tabular}{llcccc}
\hline Rank & Country & pppGDPpc & HALE & Gini & IHLI \\
\hline 138 & Burkina Faso & 1,423 & 49.7 & 0.396 & 42,728 \\
139 & Rwanda & 1,368 & 56.2 & 0.472 & 40,597 \\
140 & Ethiopia & 1,074 & 54.0 & 0.324 & 39,199 \\
141 & Guinea-Bissau & 1,400 & 48.8 & 0.436 & 38,542 \\
142 & Togo & 1,226 & 51.1 & 0.421 & 36,285 \\
143 & Liberia & 1,086 & 51.6 & 0.356 & 36,076 \\
144 & Sierra Leone & 1,200 & 43.9 & 0.383 & 32,503 \\
145 & Malawi & 1,033 & 50.4 & 0.435 & 29,415 \\
146 & Niger & 814 & 49.4 & 0.359 & 25,782 \\
147 & Mozambique & 918 & 47.6 & 0.440 & 24,464 \\
148 & Burundi & 726 & 50.3 & 0.368 & 23,082 \\
149 & Haiti & 1,502 & 32.3 & 0.529 & 22,851 \\
\hline
\end{tabular}

Source: Solt (2019); World Bank (2019), WHO (2019) and own calculations.

Open Access This article is published under the terms of the Creative Commons Attribution 4.0 International License (https://creativecommons.org/licenses/by/4.0/) that allows the sharing, use and adaptation in any medium, provided that the user gives appropriate credit, provides a link to the license, and indicates if changes were made. 